\title{
Miyokard Infarktüsü Geçiren Hastalarda Sağlık Anksiyetesinin Uyku Kalitesine Etkisi
}

\author{
๑ Seher Çevik, ${ }^{1}$ ๑ Seyhan Çıtlık Sarıtaş ${ }^{2}$ \\ 1 İnönü Üniversitesi Hemşirelik Fakültesi, Hemşirelik Esasları Anabilim Dalı, Malatya \\ 2İnönü Üniversitesi Hemşirelik Fakültesi, İç Hastalıkları Hemşireliği Anabilim Dalı, Malatya
}

\begin{abstract}
Özet
Amaç: Araştırma Miyokard infarktüsü geçiren hastalarda sağlık anksiyetesinin uyku kalitesine etkisini belirlemek amacıyla yapıldı.

Yöntemler: Araştırma tanımlayıcı ve ilişki arayıcı olarak yapıldı. Araştırma Türkiye'nin doğusunda bulunan bir üniversite hastanesinin kardiyoloji servis ve yoğun bakımlarında yapıldı. Araştırmanın evrenini bahsedilen hastanenin kardiyoloji servisinde ve yoğun bakımında takibi devam eden Miyokard infarktüsü tanısı almış hastalar oluşturdu. Araştırmanın örneklemini ise güç analizi ile 0.05 yanılgı, 0.95 güven aralığıyla, evreni 0.95 temsil gücüyle 108 hasta oluşturdu. Veriler araştırmacılar tarafından oluşturulan Kişisel Tanıtım Formu, Sağlık Anksiyetesi Ölçeği ve Richards Campbell Uyku Ölçeği kullanılarak toplandı. Verilerin değerlendirilmesinde, tanımlayıc istatistik, bağımsız gruplarda t testi, Oneway ANOVA, Man Witney U, Kolerasyon ve Cronbach Alfa güvenirlik analizi kullanıldı.

Bulgular: Araştırmada katılımcıların Sağlık Anksiyetesi Ölçeği ve Richards Campbell Uyku Ölçeği puan ortalamalarının sırasıyla $22 \pm 7.2$ ve $226.2 \pm 80.4$ olduğu bulundu. Hastaların sağlık anksiyetelerinin düşük, uyku kalitelerinin ise orta düzeyin altında olduğu görüldü. Araştırmada hastaların mesleklerine ve hissettikleri göğüs ağrısı şiddetine göre uyku kalitelerinin değiştiği bulundu. Hastaların sağlıkları ile ilgili endişe duyma durumuna göre ise sağlık anksiyeteleri arasındaki farkın önemli olduğu görüldü. Araştırmada hastaların Sağlık Anksiyetesi Ölçeği ve alt boyutları ile Richards Campbell Uyku Ölçeği arasındaki ilişkinin istatistiksel olarak önemli olmadığı bulundu.

Sonuç: Çalışma sonunda Miyokard infarktüsü geçiren hastalarda sağlık anksiyetesinin uyku kalitesi ile anlamlı bir ilişkisinin olmadığı görüldü.
\end{abstract}

Anahtar sözcükler: Hasta; miyokard infarktüsü; sağlık anksiyetesi; uyku kalitesi.

\section{The Effect of Health Anxiety on Sleep Quality in the Patients who Had Myocardial Infarction}

\author{
Abstract \\ Objective: The aim of this study was to determine the effect of health anxiety on sleep quality in patients with myocardial \\ infarction \\ Methods: The research was conducted as descriptive and relationship seeker. Research cardiology service of a university \\ hospital in the east of Turkey and was held in intensive care. The population of the study consisted of myocardial infarction \\ patients who were followed up in the cardiology department and intensive care unit of the hospital. The sample of the study \\ consisted of 108 patients with a power of 0.05 error, 0.95 confidence interval and 0.95 representation power of the universe.
}

İletişim (Correspondence): Seyhan Çıtlık Sarıtaş. İnönü Üniversitesi Hemşirelik Fakültesi, İç Hastalıkları Hemşireliği Anabilim Dalı, Malatya, Turkey Telefon (Phone): +90 5304958497 E-Posta (E-mail): seyhancitlik@hotmail.com

Başvuru Tarihi (Submitted Date): 19.11.2019 Kabul Tarihi (Accepted Date): 20.04.2020

CCopyright 2020 by Turkish Society of Cardiology - Available online at www.anatoljcardiol.com

OPEN ACCESS This work is licensed under a Creative Commons Attribution-NonCommercial 4.0 International License. 
Data were collected using the Personal Identification Form, Health Anxiety Scale, and Richards Campbell Sleep Scale. Data were analyzed using descriptive statistics, independent samples t test, Oneway ANOVA, Man Witney U, Colonation and Cronbach Alpha reliability analysis.

Results: The mean scores of Health Anxiety Scale and Richards Campbell Sleep Scale were $22 \pm 7.2$ and 226.2 \pm 80.4 , respectively. The patients' health anxiety was low and their sleep quality was below the moderate level. In the study, it was found that sleep quality of the patients changed according to their occupation and the severity of chest pain. There was a significant difference between the health anxiety levels of the patients according to their anxiety about their health. In the study, it was found that the relationship between the Health Anxiety Scale and the sub-dimensions of Richards Campbell Sleep Scale was not statistically significant.

Conclusion: At the end of the study, it was seen that there was no significant relationship between health anxiety and sleep quality in patients with myocardial infarction.

Keywords: Health anxiety; myocardial infarction; patient; sleep quality.

Cite this article as: Çevik S, Çıtlık Sarıtaş S. The Effect of Health Anxiety on Sleep Quality in the Patients who Had Myocardial Infarction. Turk J Cardiovasc Nurs 2020;11(24):16-22.

$\mathrm{K}^{\mathrm{s}}$ ardiyovasküler hastalıklar dünya çapında en büyük mortalite ve morbidite sebebi olmaya başlamıştır. Miyokard infarktüsü (MI) hem hasta yakınları hem de hastalar için travma yaratan mortalite oranı yüksek bir hastalıktır ve her yıl dünya çapında yaklaşık 32.4 insanda görüldüğü bildirilmiştir. ${ }^{[1]}$ MI koroner kan akımının azalması sonucu, en az 30 dakika süren sıkıştırıcı tarzda, retrosternal bölgede, kola, sırta yayılan, bazı hastalarda epigastrik bölgede hissedilen travmatik bir olaydır. MI, hastaların yaşam kalitelerine etki etmekle kalmayıp ciddi yaşam değişikliklerine de sebep olmaktadır. MI, ani gelişmesi ve ölüm riskinin yüksek olması sebebiyle hastalarda anksiyete oluşturabilmektedir. ${ }^{[2]}$

Sağlık anksiyetesi, herhangi bir hastalığı olmadığı halde, normal olan duyumların olumsuz yönde aşırı yorumlanmasıdır. Ciddi bir hastalığın varlığı ve var olan bu hastalığın ciddi sonuçlarının varlığı şeklinde iki ana bileşene sahiptir. Hatta bu iki bileşenin birbirini takip eden bir döngüye dönüştüğü söylenebilmektedir. ${ }^{[3]}$ Literatürde herhangi bir fiziksel hastalığı olmadığı halde hastaneye başvuran kişilerin sayısının \%20 ile \%84 arasında değiştiği yer almaktadır. ${ }^{[4]}$ Bireyin kişilik yapısı, geçmiş deneyimleri, tekrarlı hastane yatışları ya da zaten var olan hastalıklar ve bu hastalıkların semptomları gibi faktörler bireyin sağlık anksiyetesini etkileyebilmektedir. ${ }^{[5]} \mathrm{Ml}$ gibi hastalıklarda, gerek ciddiyetleri gerekse semptomları sebebiyle hastaların yaşam kalitesinde değişiklik meydana gelebilmektedir. Hastaların uyku örüntüsündeki değişiklikler de bu semptomlar arasındadır. Uyku örüntüsü ise yaşam stili, çevre, iş, sosyal yaşam, ekonomik durum, genel sağlık durumu ve stres gibi faktörlerden etkilenmektedir. ${ }^{[6]}$

Literatür incelendiğinde MI geçiren hastalarda sağlık anksiyetesini ve uyku kalitesini bir arada inceleyen çalışmaya rastlanmamıştır. Buradan hareketle bu çalışmanın amacı MI geçiren hastalarda sağlık anksiyetesinin uyku kalitesine etkisini incelemektir.

\section{Gereç ve Yöntem}

Araştırma tanımlayıcı ve ilişki arayıcı olarak, Türkiye'nin doğusunda bulunan bir üniversite hastanesinin kardiyoloji servisi ve yoğun bakımında yapıldı. Araştırmanın evrenini bahsedilen hastanenin kardiyoloji servisinde ve yoğun bakımında takibi devam eden MI tanısı almış yetişkin hastalar oluşturdu. Araştırmanın örneklemini ise güç analizi ile 0.05 yanılgı, 0.95 güven aralığıyla, evreni 0.95 temsil gücüyle 108 hasta oluşturdu. Araştırmaya alınma kriterlerine uyan, herhangi bir psikiyatrik tanısı ve iletişim engeli bulunmayan hastalar evrenden olasılıksız rastlantısal örnekleme yöntemi ile örnekleme sayısına ulaşıııncaya kadar araştırmaya alındı.

\section{Veri Toplama}

Araştırmanın verileri Ekim- Kasım 2019 tarihleri arasında araştırmacılar tarafından yüz yüze görüşme tekniği kullanılarak yaklaşık 15-20 dakikada toplandı. Veriler araştırmacılar tarafından oluşturulan Kişisel Tanıtım Formu, Sağlık Anksiyetesi Ölçeği ve Richards Campbell Uyku Ölçeği kullanılarak toplandı.

Kişisel Tanıtım Formu; Kişisel tanıtım formu, araştırma kapsamına alınan hastaların sosyo-demografik verilerinin toplanması amacıyla araştırmacı tarafından oluşturulmuştur. Formda 6'sı sosyo-demografik, $5^{\prime} \mathrm{i}$ ise MI ile ilgili özellikleri sorgulayan toplam 11 soru bulunmaktadır. ${ }^{\text {[7] }}$

Sağlık Anksiyetesi Ölçeği (SAÖ); Ölçek Salkovskis ve arkadaşları tarafından 2002 yılında geliştirilmiş olup, Türkçe geçerlilik ve güvenirlilik çalışması Aydemir ve arkadaşları tarafından 2013 yılında yapıımıştır. ${ }^{[8,9]}$ Ölçek 18 maddeden oluşmaktadır ve 0-3 arasında puanlanmaktadır. Ölçekten en az 0 en fazla 54 puan alınabilmektedir. Ölçekten alınan yüksek puanlar sağlık anksiyetesinin yüksek olduğunu göstermektedir. İki faktörlü bir yapıya sahip olan ölçeğin ilk faktörü, ölçeğin ilk 14 maddesini içermektedir ve bedensel 
belirtilere aşırı duyarlılık ve kaygı boyutunu oluşturmaktadır, ikinci faktörü ise son 4 maddeyi içermekte olup hastalığın olumsuz sonuçlarıyla ilişsili boyuttur. Ölçeğin Cronbach alfa iç tutarlılık katsayısı 0.91 'dir. ${ }^{[9]} \mathrm{Bu}$ araştırmada ise Cronbach alfa iç tutarlılık sayısı 0.78 bulunmuştur.

Richards Campbell Uyku Ölçeği (RCUÖ); Richards tarafından geliştirilen ölçek 6 maddeden oluşmaktadır. ${ }^{[10]}$ Türkçe güvenirlik geçerliliği Özlü ve Özer tarafından 2015 yılında yapılmıştır. ${ }^{[1]]}$ Ölçekte hastaların her madde için 0 ile 100 puan arasında değerlendirme yapmaları istenmektedir. Ortamdaki gürültü düzeyini değerlendiren 6 . madde ise toplam puan değerlendirmesine dahil edilmemektedir. Ölçekten alınan toplam puan soru sayısına bölünerek sonuç bulunmakta e"0-25" puan "çok kötü uykuyu", "76-100" puan "çok iyi uykuyu" ifade etmektedir. Ölçekten en az 0 en çok 100 puan alınabilmektedir. Ölçekten alınan puanın artması uyku kalitesinin arttığını göstermektedir. Ölçeğin Cronbach alfa iç tutarlılık sayısı 0.91 'dir. ${ }^{[11]} \mathrm{Bu}$ araştırmada ise Cronbach alfa iç tutarlılık sayısı 0.86 bulunmuştur.

\section{Araştırmanın Etik Yönü}

Araştırmaya başlamadan önce, araştırmanın yapılacağı Kardiyoloji Anabilim Dalı Başkanlığı'ndan resmi izin ve aynı üniversitenin Sağlık Bilimleri Bilimsel Araştırma ve Yayın Etik Kurulu'ndan etik (2019) onay alındı. Araştırmaya katılmayı kabul eden bireyler, Helsinki Bildirgesi doğrultusunda, çalışmanın amacı, veri toplama işleminin nasıl yapılacağı ve ne kadar süreceği hakkında bilgilendirilerek sözlü onamları alındı.

\section{Verilerin Değerlendirilmesi}

Verilerin değerlendirilmesinde, tanımlayıc istatistik, bağımsız gruplarda t testi, Oneway ANOVA, Mann Witney $U$, Bonferoni, Kolerasyon ve Cronbach Alfa güvenirlik analizi kullanıldı. Sonuçlar \%95'lik güven aralığında, anlamlılık $p<0.05$ düzeyinde değerlendirildi.

\section{Bulgular}

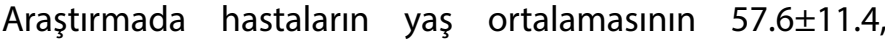
\%55.6'sının kadın, \%62'sinin lise mezunu olduğu, \%79.6' sının evli, \%33.3'ünün ev hanımı, \%58.3'ünün ekonomik durumunun orta olduğu, \%91.7'sinin daha önce Ml geçirmediği, \%49.1'inin şiddetli göğüs ağrısı yaşadığı, \%52.8' inin ailesinde MI geçiren bir kişi olduğu, \%59.3'ünün sağlıkları ile ilgili bazen endişe yaşadığı bulundu (Tablo 1).

Araştırmada katılımcıların SAÖ ve RCUÖ puan ortalamalarının sırasıyla $22 \pm 7.2$ ve $226.2 \pm 80.4$ olduğu bulundu. Hastaların sağlık anksiyetelerinin düşük, uyku kalitelerinin ise orta düzeyin altında olduğu görüldü (Tablo 2).

\begin{tabular}{|c|c|c|}
\hline Hastaya ait özellikler & Sayı (n) & $\%$ \\
\hline \multicolumn{3}{|l|}{ Yaş } \\
\hline$(\bar{X} \pm S S=57.6 \pm 11.4)$ & 108 & \\
\hline \multicolumn{3}{|l|}{ Cinsiyet } \\
\hline Kadın & 60 & 55.6 \\
\hline Erkek & 48 & 44.4 \\
\hline \multicolumn{3}{|l|}{ Öğrenim durumu } \\
\hline Okuryazar & 14 & 13 \\
\hline İlköğrenim & 27 & 25 \\
\hline Lise & 67 & 62 \\
\hline \multicolumn{3}{|l|}{ Medeni durum } \\
\hline Bekar & 22 & 20.4 \\
\hline Evli & 86 & 79.6 \\
\hline \multicolumn{3}{|l|}{ Meslek } \\
\hline Memur & 21 & 19.4 \\
\hline İşçi & 12 & 11.1 \\
\hline Serbest meslek & 10 & 9.3 \\
\hline Emekli & 29 & 26.9 \\
\hline Ev hanımı & 36 & 33.3 \\
\hline \multicolumn{3}{|l|}{ Ekonomik durum } \\
\hline İyi & 33 & 30.6 \\
\hline Orta & 63 & 58.3 \\
\hline Kötü & 12 & 11.1 \\
\hline \multicolumn{3}{|c|}{ Daha önce Ml geçirme durumu } \\
\hline Evet & 9 & 8.3 \\
\hline Hayır & 99 & 91.7 \\
\hline \multicolumn{3}{|c|}{ Hastanın göğüs ağrısı şiddeti } \\
\hline Hafif & 10 & 9.3 \\
\hline Orta & 45 & 41.7 \\
\hline Şiddetli & 53 & 49.1 \\
\hline \multicolumn{3}{|c|}{ Ailede IM geçiren kişi varlığı } \\
\hline Evet & 57 & 52.8 \\
\hline Hayır & 51 & 47.2 \\
\hline \multicolumn{3}{|c|}{ Sağlıkları ile ilgili endişe duyma durumu } \\
\hline Her zaman & 8 & 7.4 \\
\hline Bazen & 64 & 59.3 \\
\hline Hiç & 36 & 33.3 \\
\hline
\end{tabular}

Tablo 2. Katılımçıların Sağlık Anksiyetesi Ölçeği ve Richards Campbell Uyku Ölçeği Puan Ortalamaları

\begin{tabular}{|c|c|c|}
\hline Ölçek & $\overline{\mathrm{X}} \pm \mathrm{SS}$ & $\begin{array}{l}\text { Alınan Min.- } \\
\text { Max. Puanlar }\end{array}$ \\
\hline SAÖ toplam & $22 \pm 7.2$ & $3-65$ \\
\hline $\begin{array}{l}\text { Bedensel belirtilere aşırı } \\
\text { duyarlılık ve kaygı boyutu }\end{array}$ & $16.7 \pm 4.8$ & $3-45$ \\
\hline $\begin{array}{l}\text { Hastalığın olumsuz sonuçları } \\
\text { boyutu }\end{array}$ & $5.2 \pm 5$ & $0-53$ \\
\hline RCUÖ toplam & $226.2 \pm 80.4$ & $0-480$ \\
\hline
\end{tabular}

SAÖ: Sağlık Anksiyetesi Ölçeği; RCUÖ: Richards Campbell Uyku Ölçeği. 
Araştırmada kadınların SAÖ bedensel belirtilere aşırı duyarlılık ve kaygı alt boyut ortalamalarının erkeklerden daha yüksek olduğu ve aralarındaki farkın ise istatistiksel olarak önemli olduğu bulundu $(p<0.05)$. Evli hastaların ise SAÖ puan ortalamalarının bekar hastalara göre önemli düzeyde yüksek olduğu görüldü $(p<0.05)$. Mesleklerine göre hastaların RCUÖ puan ortalaması incelendiğinde, gruplar arasında önemli fark olduğu bulundu $(p<0.05)$. Yapılan bonferroni düzeltmesi sonucunda gruplar arasındaki farkın ise ev hanımı olan gruptan kaynaklandığı tespit edildi. Çalışma sonucunda şiddetli göğüs ağrısı yaşayan hastaların uyku kalitelerinin daha düşük olduğu bulundu $(p<0.05)$. Araştırmada sağlıkları ile ilgili her zaman endişe duyan bireylerin SAÖ puan ortalamalarının diğer gruplara göre önemli düzeyde daha yüksek olduğu görüldü $(p<0.05)$ (Tablo 3).

Araştırmada hastaların SAÖ ve alt boyutları ile RCUÖ arasındaki ilişkinin istatistiksel olarak önemli olmadığı bulundu ( $p>0.05)$. Ml geçiren hastaların sağlık anksiyeteleri uyku kalitelerini etkilememektedir (Tablo 4).

\section{Tartışma}

Miyokard infarktüsü geçiren hastalarda uyku sorunları ve yaşam kalitesinde değişiklik en sık görülen semptomlar arasındadır. ${ }^{[12]}$ Sağlık anksiyetesi gibi durumlar ise bu semptomların daha da ağırlaşmasına sebep olabilmektedir. Hastaların yaşam kalitesinin arttırıması, daha da önemlisi yeniden $\mathrm{Ml}$ geçirme risklerinin azaltılması için uyku kalitelerinin arttırılması ve sağlık anksiyetelerinin kontrol altına alınması son derece önemlidir. ${ }^{[13]}$

Araştırmada hastaların sağlık anksiyetelerinin düşük olduğu bulundu. Literatürde MI geçiren hastaların sağlık anksiyetesini inceleyen herhangi bir çalışmaya rastlanmamıştır. Araştırmamızla farklı düzlemde olmakla beraber Gül ve ark. ${ }^{[14]}$ çalışmasında Miyofasyal ağrı sendromu yaşayan hastalarında sağlık anksiyeteleri düşük bulunmuştur. ÇaIışmada MI geçiren hastaların uyku kalitelerinin ise orta düzeyin altında olduğu görüldü. Tenekeci ve Kara'nın MI geçiren hastalarda uyku kalitesi ve yorgunluk ilişkisi başIıklı çalışmasında, araştırmamıza paralel sonuçlar bulunmuştur. ${ }^{[15]}$

Sağlık anksiyetesi birçok faktörden etkilenebilmektedir. Araştırmada kadınların bedensel belirtilere aşıı duyarlılık ve kaygı düzeylerinin erkeklere göre anlamlı düzeyde daha yüksek olduğu bulundu. Benzer şekilde Feder ve ark. ${ }^{[16]}$ çaıışmasında kadın cinsiyet, yalnız yaşıyor olmak ve ileri yaş, tıbben açıklanamayan belirtiler ile ilişkili sosyodemografik etkenler olarak belirlenmiştir. Ayrıca araştırmada eğitim du- rumu, meslek ve ekonomik durumun sağlık anksiyetesini etkilemediği bulunurken, medeni durumun sağlık anksiyetesi üzerinde etkili olduğu görüldü. Benzer çalışmaya rastlanmadı, eğitim durumu, meslek ve ekonomik durumun sağlıkla ilgili şüphe duyulan durumlarda arka planda kaldığı ve eşlerin birbirlerinin farkındalıklarını arttırdığı ayrıca doktora gitmesi konusunda eşlerini yönlendirmede etkili olabilecekleri düşünülebilir.

Çalışmada hastaların uyku kalitelerinin cinsiyet, eğitim durumu, medeni durum ve ekonomik duruma göre değişmediği görülürken, mesleğe göre değişiklik gösterdiği bulundu. Tenekeci ve Kara'nın çalışmasında MI geçiren hastaların uyku kalitelerinin cinsiyet, eğitim durumu ve ekonomik durumdan etkilenmediği görülürken, medeni duruma göre uyku kalitelerinin değiştiği belirtilmiştir. [14] Grander ve ark. ${ }^{[17]}$ tarafından yapılan bir çalışmada bekarlarda uyku problemlerinin daha sık görüldüğü bulunurken, Troxel ve ark., ${ }^{[18]}$ evlilikteki sorunlar sebebiyle evli bireylerin uyku kalitelerinin daha düşük olduğunu bildirmiştir.

Araştırma sonuçlarına göre, hastaların daha önce MI geçirme durumu, göğüs ağrısı şiddeti, ailelerinde Ml geçiren herhangi bir kişinin olması sağlık anksiyetelerini etkilememektedir. Hastaların MI gibi riskli ve takip gerektiren hastalığa sahip olması ve sık sık semptomlarla ilgili kontrole gitmeleri sebebiyle adı geçen durumların bireyin sağlık anksiyetesi üzerinde etkili olmadığı düşünülebilir. Buna karşın çalışmada sağlığı ile ilgili her zaman endişe duyan hastaların sağlık anksiyetelerinin daha yüksek olduğu görüldü. Sağlığı ile ilgili her zaman endişe duyan bireylerin anksiyeteleri sebebiyle bedensel duyumlarının daha yüksek olduğu, dolayısıyla sağlık anksiyetelerinin de daha yüksek olabileceği söylenebilir. ${ }^{[19]}$

Hastaların uyku kaliteleri ile daha önce MI geçirme durumu, göğüs ağrısı şiddeti, ailelerinde MI geçiren herhangi bir kişinin olması ve sağlıkları ile ilgili endişe duyma durumu arasındaki ilişki incelendiğinde, göğüs ağrısı şiddeti dışında uyku kalitesini önemli düzeyde etkileyen faktöre rastlanmamıştır. Yine Tenekeci ve Kaya'nın çalışmasında benzer şekilde MI geçirme sayısının uyku kalitesinde değişiklik yapmadığı bulunmuştur. ${ }^{[14]}$ Ailelerinde $\mathrm{MI}$ geçirmiş birey olup-olmamasının hastanın uyku kalitesini etkilememesi, geçmiş deneyimlerin bazen farkındalık yaratıp kabullenmeyi sağladığı, bazen de bireyi bekleyen sürecin belli olmamasının bireyi daha rahat olmaya yönlendirebileceği ile açıklanabilir. Sağlıkları ile ilgili endişeli olma düzeyi ise $\mathrm{MI}$ geçiren hastaların kontrol altında olması ve sıkı takip edilmesi sonucu uyku kalitelerini etkilemediği düşünülebilir. 


\begin{tabular}{|c|c|c|c|c|}
\hline Katılımcılara ait özellikler & SAÖ & $\begin{array}{l}\text { Bedensel belirtilere aşırı } \\
\text { duyarlılık ve kaygı boyutu }\end{array}$ & $\begin{array}{l}\text { Hastalığın olumsuz } \\
\text { sonuçları boyutu }\end{array}$ & RCUÖ \\
\hline \multicolumn{5}{|l|}{ Cinsiyet } \\
\hline Kadın & $21.4 \pm 6.3$ & $16.7 \pm 5.3$ & $4.6 \pm 2$ & $241.5 \pm 75.2$ \\
\hline Erkek & $22.7 \pm 8.2$ & $13.6 \pm 4.2$ & $6.1 \pm 7.1$ & $257.1 \pm 76.6$ \\
\hline \multirow[t]{2}{*}{ İstatistik test ve anlamlılık } & $t=-0.94$ & $t=-3.776$ & $t=0.153$ & $t=-1.499$ \\
\hline & $p=0.363$ & $\mathrm{p}=0.000$ & $\mathrm{p}=0.879$ & $p=0.179$ \\
\hline \multicolumn{5}{|l|}{ Öğrenim durumu } \\
\hline Okuryazar & $21.5 \pm 7.3$ & $16.9 \pm 5.7$ & $4.5 \pm 2.3$ & $246 \pm 57.1$ \\
\hline Illköğrenim & $20.6 \pm 4.4$ & $15.8 \pm 3.4$ & $4.8 \pm 1.8$ & $236.1 \pm 94.3$ \\
\hline Lise & $22.6 \pm 8$ & $17 \pm 5.1$ & $5.6 \pm 6.1$ & $218.2 \pm 78.4$ \\
\hline \multirow[t]{2}{*}{ İstatistik test ve anlamlılık } & $K W=2.058$ & $K W=2.815$ & $K W=1.973$ & $K W=0.504$ \\
\hline & $p=0.357$ & $p=0.245$ & $p=0.373$ & $p=0.777$ \\
\hline \multicolumn{5}{|l|}{ Medeni durum } \\
\hline Bekar & $19.2 \pm 7.1$ & $14.7 \pm 5.4$ & $4.4 \pm 2.3$ & $232 \pm 93.6$ \\
\hline Evli & $22.7 \pm 7$ & $17.1 \pm 4.6$ & $5.5 \pm 5.5$ & $224.8 \pm 77.3$ \\
\hline \multirow[t]{2}{*}{ İstatistik test ve anlamlılık } & $Z=-1.993$ & $Z=-0.301$ & $Z=-2.060$ & $Z=-0.964$ \\
\hline & $p=0.046$ & $p=0.763$ & $p=0.069$ & $p=0.335$ \\
\hline \multicolumn{5}{|l|}{ Meslek } \\
\hline Memur & $21.8 \pm 3.6$ & $17.2 \pm 3.3$ & $4.5 \pm 1.8$ & $226.4 \pm 67.8$ \\
\hline İşçi & $19.8 \pm 5.2$ & $15.5 \pm 3.7$ & $4.2 \pm 2.1$ & $187.5 \pm 105.2$ \\
\hline Serbest meslek & $23 \pm 11.5$ & $18 \pm 10.6$ & $5 \pm 2$ & $200 \pm 75.2$ \\
\hline Emekli & $22 \pm 4.8$ & $16.8 \pm 3.4$ & $5.2 \pm 1.9$ & $213.6 \pm 83.2$ \\
\hline Ev hanımı & $22.4 \pm 9.3$ & $16.2 \pm 4.6$ & $6.1 \pm 8.2$ & $256.5 \pm 69.9$ \\
\hline \multirow[t]{2}{*}{ İstatistik test ve anlamlılık } & $K W=0.352$ & $K W=0.474$ & $K W=0.524$ & $K W=2.543$ \\
\hline & $p=0.842$ & $p=0.755$ & $p=0.718$ & $p=0.044$ \\
\hline \multicolumn{5}{|l|}{ Ekonomik durum } \\
\hline İyi & $22.5 \pm 6.4$ & $17.2 \pm 6$ & $5.2 \pm 1.4$ & $225 \pm 61.3$ \\
\hline Orta & $22.2 \pm 7.4$ & $16.7 \pm 4$ & $5.4 \pm 6.4$ & $228 \pm 82.8$ \\
\hline Kötü & $19.4 \pm 7.6$ & $15 \pm 5.3$ & $4.4 \pm 2.6$ & $220.8 \pm 115.2$ \\
\hline \multirow[t]{2}{*}{ İstatistik test ve anlamlılık } & $\mathrm{KW}=0.884$ & $\mathrm{KW}=0.045$ & $\mathrm{KW}=0.958$ & $\mathrm{KW}=0.229$ \\
\hline & $p=0.416$ & $p=0.956$ & $\mathrm{p}=0.387$ & $\mathrm{p}=0.796$ \\
\hline \multicolumn{5}{|l|}{ Daha önce MI geçirme durumu } \\
\hline Evet & $20.7 \pm 4.5$ & $16.6 \pm 3.3$ & $4.1 \pm 2.4$ & $238.3 \pm 38.5$ \\
\hline Hayır & $22.1 \pm 7.4$ & $16.7 \pm 5$ & $5.4 \pm 5.2$ & $225.2 \pm 83.2$ \\
\hline \multirow[t]{2}{*}{ İstatistik test ve anlamlılık } & $Z=-0.379$ & $Z=-0.145$ & $Z=-0.959$ & $Z=-0.467$ \\
\hline & $\mathrm{p}=0.705$ & $\mathrm{p}=0.885$ & $\mathrm{p}=0.338$ & $\mathrm{p}=0.64$ \\
\hline \multicolumn{5}{|l|}{ Hastanın göğüs ağrısı şiddeti } \\
\hline Hafif & $25.9 \pm 10.1$ & $20.1 \pm 9.6$ & $5.8 \pm 0.9$ & $220.5 \pm 52.5$ \\
\hline Orta & $21.9 \pm 8.7$ & $16 \pm 4.3$ & $5.8 \pm 7.4$ & $223.6 \pm 91.7$ \\
\hline Şiddetli & $21.3 \pm 4.6$ & $16.5 \pm 3.7$ & $4.7 \pm 2.1$ & $201.6 \pm 75.5$ \\
\hline \multirow[t]{2}{*}{ İstatistik test ve anlamlılık } & $\mathrm{KW}=1.771$ & $K W=1.294$ & $K W=2.819$ & $K W=0.173$ \\
\hline & $p=0.413$ & $\mathrm{p}=0.524$ & $\mathrm{p}=0.244$ & $p=0.017$ \\
\hline \multicolumn{5}{|l|}{ Ailede IM geçiren kişi varlığı } \\
\hline Evet & $21 \pm 5.2$ & $16.3 \pm 3.8$ & $4.7 \pm 2.2$ & $224.5 \pm 76.8$ \\
\hline Hayır & $23 \pm 8.8$ & $17 \pm 5.8$ & $5.9 \pm 6.9$ & $228.2 \pm 85$ \\
\hline \multirow{2}{*}{ İstatistik test ve anlamlılık } & $t=-1.387$ & $t=-0.777$ & $t=-1.262$ & $t=-0.234$ \\
\hline & $\mathrm{p}=0.169$ & $\mathrm{p}=0.439$ & $\mathrm{p}=0.233$ & $\mathrm{p}=0.815$ \\
\hline \multicolumn{5}{|c|}{ Sağlıkları ile ilgili endişe duyma durumu } \\
\hline Her zaman & $24.1 \pm 2.4$ & $15.2 \pm 2$ & $4.8 \pm 1.2$ & $274.3 \pm 49.9$ \\
\hline Bazen & $21.1 \pm 5.9$ & $16.3 \pm 4.7$ & $4.7 \pm 2.2$ & $228.2 \pm 79.8$ \\
\hline Hiç & $20 \pm 9.2$ & $17.6 \pm 5.4$ & $6.3 \pm 8.1$ & $212 \pm 84$ \\
\hline \multirow{2}{*}{ İstatistik test ve anlamlılık } & $K W=1.086$ & $K W=1.304$ & $K W=0.213$ & $K W=3.854$ \\
\hline & $p=0.047$ & $\mathrm{p}=0.254$ & $\mathrm{p}=0.645$ & $\mathrm{p}=0.512$ \\
\hline
\end{tabular}

SAÖ: Sağlık Anksiyetesi Ölçeği; RCUÖ: Richards Campbell Uyku Ölçeği. 


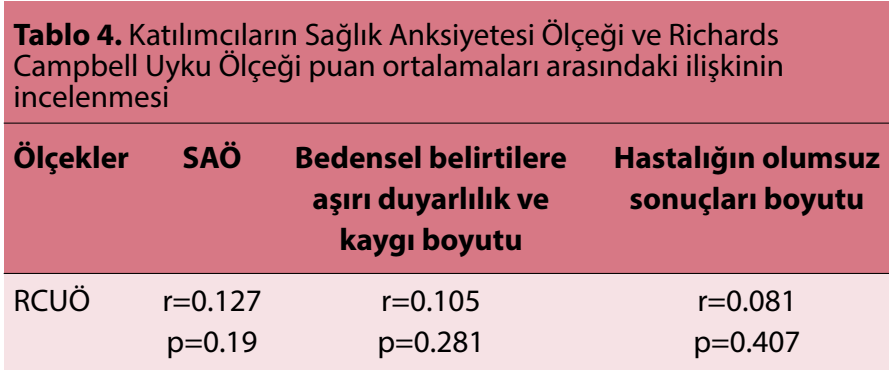

SAÖ: Sağlık Anksiyetesi Ölçeği; RCUÖ: Richards Campbell Uyku Ölçeği.

Fiziksel yakınmalar bireyin uykuya dalmada güçlük yaşamasına sebep olur. Simpson ve ark. ${ }^{[20]}$ çalışmasının araştırma sonucumuza paralel olarak ağrı şiddetinin uyku kalitesini etkilediği bildirilmiştir.

Araştırma verilerinden elde edilen sonuçlara göre $\mathrm{MI}$ geçiren hastalarda sağlık anksiyetesi ve uyku kalitesi arasında anlamlı bir ilişki olmadığı bulunmuştur. Literatürde benzer çalışmaya rastlanmamıştır. Yapılan çalışmalar sağlık anksiyetesinin kişilik özelliklerinden kaynaklandığı bildirmiştir. [21, 22] Buradan hareketle sonucun örneklem özelliğinden kaynaklandığı söylenebilir.

\section{Sonuç}

Araştırma sonucunda MI geçiren hastaların sağlık anksiyetelerinin düşük, uyku kalitelerinin ise ortanın altında olduğu bulundu. Çalışma sonunda MI geçiren hastalarda sağlık anksiyetesinin uyku kalitesi ile anlamlı bir ilişkisinin olmadığı görüldü. Bu sonuçlar doğrultusunda hemşirelerin, MI geçiren hastaların sağlık anksiyetelerini ve uyku kalitelerini değerlendirmeleri, sağlık anksiyetesi ve uyku kalitesini etkileyen faktörleri belirlemesi, özellikle sağlık anksiyetesi konusunda farkındalık eğitimlerinin yapılması ve araştırmanın daha büyük ve farklı gruplarda tekrarlanması önerilebilir.

Etik Kurul Onayı: İnönü Üniversitesi Sağlık Bilimleri Bilimsel Araştırma ve Yayın Etik Kurulu. Karar No: 2019/413; toplantı tarihi: 12.11.2019.

Hakem Değerlendirmesi: Dış bağımsız.

Çıkar Çatışması: Yazarlar arasında herhangi bir çıkar çatışması bulunmamaktadır.

Yazarlık Katkıları: Konsept: S.C., S.C.S.; Dizayn: S.C., S.C.S.; Veri Toplama veya Işleme: S.C.; Analiz veya Yorumlama: S.C., S.C.S.; Literatür Arama: S.C., S.C.S.; Yazan: S.C., S.C.S.

\section{Kaynaklar}

1. Reed GW, Rossi JE, Cannon CP. Acute myocardial infarction. Lancet 2017;389(10065):197-210. [CrossRef]

2. Dural G, Çıtlık Sarıtaş S. Miyokard infarktüsünde ev tabanlı eğitim ve yaşam kalitesi. Journal of Cardiovascular Nursing 2017;8(17):86-94. [CrossRef]

3. Bailer J, Kerstner T, Witthöft M, Diener C, Mier D, Rist F. Health anxiety and hypochondriasis in the light of DSM-5. Anxiety Stress Coping 2016;29(2):219-239. [CrossRef]

4. Krautwurst $S$, Gerlach AL, Witthöft M. Interoception in pathological health anxiety. J Abnorm Psychol 2016;125(8):11791184. [CrossRef]

5. Rask CU, Munkholm A, Clemmensen L, Rimvall MK, Ørnbøl $\mathrm{E}$, Jeppesen $\mathrm{P}$, et al. Health Anxiety in Preadolescence--Associated Health Problems, Healthcare Expenditure, and Continuity in Childhood. J Abnorm Child Psychol 2016;44(4):823832. [CrossRef]

6. Tobaldini E, Costantino G, Solbiati M, Cogliati C, Kara T, Nobili $L$, et al. Sleep, sleep deprivation, autonomic nervous system and cardiovascular diseases. Neurosci Biobehav Rev 2017;74:321-329. [CrossRef]

7. Francis GS, Tang WH. Pathophysiology of congestive heart failure. Rev Cardiovasc Med 2003;4 Suppl 2:S14-S20.

8. Salkovskis PM, Rimes KA, Warwick HM, Clark DM. The Health Anxiety Inventory: development and validation of scales for the measurement of health anxiety and hypochondriasis. Psychol Med 2002;32(5):843-853. [CrossRef]

9. Aydemir Ö, Kirpinar I, Sati T, Uykur B, Cengisiz, C. Sağlık Anksiyetesi Ölçeği'nin Türkçe için güvenilirlik ve geçerlilik çaIışması. Archives of Neuropsychiatry/Noropsikiatri Arsivi 2013;50(4)325-331. [CrossRef]

10. Richards KC, O'Sullivan PS, Phillips RL. Measurement of sleep in critically ill patients. J Nurs Meas 2000;8(2):131-144. [CrossRef]

11. Özlü ZK, Özer N. Richard-Campbell uyku ölçeği geçerlilik ve güvenilirlik çalışması. Journal of Turkish Sleep Medicine 2015;2:29-32. [CrossRef]

12. Olgun S, Kaptan G, Büyükünal SK. Miyokard infarktüsü geçirmiş hastaların yaşam kalitesinin değerlendirilmesi. Sağlık Bilimleri Ve Yaşam Dergisi 2016;1(1):6-15.

13. Mert KU, Mert GO, Dural M, Unalır A. Akut ST elevasyonlu miyokard enfarktüsü sonrası yaşam kalitesi (EQ5D). MN Kardiyoloji 2016;23:182-191.

14. Gül Aí, Uçar M, Sarp Ü, Karaaslan Ö, Börekçi E. Miyofasyal ağrı sendromu ve sağlık anksiyetesi arasındaki ilişki. Uluslararası Klinik Araştırmalar Dergisi 2014;2(3):89-92.

15. Tenekeci EG, Kara B. Miyokart infarktüsü geçiren bireylerde uyku kalitesi ve yorgunluk arasındaki ilişki. Gülhane Tıp Derg 2016;58:366-372.

16. Feder A, Olfson M, Gameroff M, Fuentes M, Shea S, Lantigua $\mathrm{RA}$, et al. Medically unexplained symptoms in an urban general medicine practice. Psychosomatics 2001;42(3):261268. [CrossRef]

17. Grandner MA, Williams NJ, Knutson KL, Roberts D, Jean-Louis G. Sleep disparity, race/ethnicity, and socioeconomic position. Sleep Med 2016;18:7-18. [CrossRef]

18. Troxel WM, Robles TF, Hall M, Buysse DJ. Marital quality and the marital bed: examining the covariation between rela- 
tionship quality and sleep. Sleep Med Rev 2007;11(5):389404. [CrossRef]

19. Güleç YM, Hocaoğlu Ç, Durmuş İ. Kalple ilişkili olmayan göğüs ağrısı olan hastalarda psikiyatrik eş tanı. Klinik Psikiyatri Dergisi 2007;10:7-13.

20. Simpson NS, Scott-Sutherland J, Gautam S, Sethna N, Haack $M$. Chronic exposure to insufficient sleep alters processes of pain habituation and sensitization. Pain 2018;159(1):33-40.
21. Fergus TA, Limbers CA, Griggs JO, Kelley LP. Somatic symptom severity among primary care patients who are obese: examining the unique contributions of anxiety sensitivity, discomfort intolerance, and health anxiety. J Behav Med 2018;41(1):43-51. [CrossRef]

22. Kandemir G, Ak I. Tıbben açıklanamayan belirtilerin psikiyatrik yönü. Psikiyatride Güncel Yaklaşımlar 2013;5(4):479-506. 